\title{
Polycyclic Aromatic Hydrocarbons (PAHs) in Urban Street Dust of Huanggang, Central China: Status, Sources and Human Health Risk Assessment
}

\author{
Jia Liu' ${ }^{1}$, Jiaquan Zhang ${ }^{2 *}$, Changlin Zhan², Hongxia Liu ${ }^{2}$ Li Zhang ${ }^{2}$, Tianpeng Hu ${ }^{3}$, \\ Xinli Xing ${ }^{3}$, Chengkai $\mathrm{Qu}^{4}$ \\ ${ }^{1}$ School of Energy and Environmental Engineering, University of Science and Technology Beijing, Beijing 100083, China \\ ${ }^{2}$ School of Environmental Science and Engineering, Hubei Key Laboratory of Mine Environmental Pollution Control and \\ Remediation, Hubei Polytechnic University, Huangshi 435003, China \\ ${ }^{3}$ State Key Laboratory of Biogeology and Environmental Geology, School of Environmental Studies, China University of \\ Geosciences, Wuhan, 430074, China \\ ${ }^{4}$ College of Urban and Environmental Sciences, Northwest University, Xi'an 710127, China
}

\begin{abstract}
Twenty-one street dust samples were collected in Huanggang City, Hubei Province, Central China. Sixteen priority polycyclic aromatic hydrocarbons (PAHs) were determined by gas chromatography-mass spectrometry (GC-MS). Concentrations of $\sum_{16}$ PAHs ranged from $622.97 \mu \mathrm{g} \mathrm{kg}^{-1}$ to $4340.67 \mu \mathrm{g} \mathrm{kg}^{-1}$ with an average of $1862.10 \mu \mathrm{g} \mathrm{kg}$. $\mathrm{Among}^{-1}$ these PAHs, high-molecular-weight PAHs (four to six rings), which are the predominant PAH contributors in street dust, accounted for $55 \%-73 \%$ of the total PAHs. Mean concentrations of the PAHs among the four functional districts followed the order: education district $>$ traffic area > business district $>$ residential area. However, the individual PAH concentrations exhibited weak correlations with the total organic carbon. Based on the isomer ratios of the PAHs, biomass and coal combustion, and petroleum input were two key factors controlling PAH levels in this study. At a 95\% confidence interval, the total incremental lifetime cancer risks for children, adolescents and adults approximated $10^{-6}-1.5 \times 10^{-5}$. These values were higher than the baseline value for acceptable risk $\left(10^{-6}\right)$, indicating a potential carcinogenic risk.
\end{abstract}

Keywords: Polycyclic aromatic hydrocarbons (PAHs); Street dust; Source analysis; Health risk assessment.

\section{INTRODUCTION}

Polycyclic aromatic hydrocarbons (PAHs) refer to a group of lipophilic chemicals comprising two or more fused aromatic rings. Hundreds of PAHs predominantly form from incomplete combustion or pyrolysis of organic matter from anthropogenic activities (Mastral and Callen, 2000). With the rapid development of industrialisation and urbanisation, PAHs have become ubiquitous environmental pollutants and caused serious contamination problems associated with continuously increasing emission (Xu et al., 2006; Xing et al., 2011). In China, PAHs mainly originate from emission of biomass burning, domestic coal combustion and coking industry (Xu et al., 2006). PAHs pose a significant concern to human health due to their high toxicity, mutagenicity and carcinogenicity (Boström et al., 2002). Under this consideration, 16 PAHs have been listed

\footnotetext{
${ }^{*}$ Corresponding author.

Tel.: +86-714-6368353; Fax: +86-714-6368835

E-mail address: zhangjiaquan@hbpu.edu.cn
}

in the U.S. Environmental Protection Agency as priority pollutants.

Street dust in urban areas provides a dominant pathway in accumulating atmospheric deposition particulates. Thus, street dust can be the main medium containing $\mathrm{PAH}$ particles via direct exposure to vehicle exhaust emissions and absorption of emitted PAHs (Mostafa et al., 2009; Martuzevicius et al., 2011). Considering the dynamic relationship of atmospheric aerosol by re-suspension and re-deposition in atmosphere, street dust, as hazardous carrier, can cause air pollution concerns (Rogge et al., 1993). Some atmospheric depositions of PAHs have become potentially significant pollutant source of PAHs in surface waters, in sediment via runoff and eventually in animals by going through the food chain (Mostafa et al., 2009). Thus, increasing literature have focused on the characteristics and potential exposure health risk of PAHs in urban street dust (Liu et al., 2007; Wang et al., 2011; Yu et al., 2014).

Huanggang City $\left(29^{\circ} 45^{\prime}-31^{\circ} 35^{\prime} \mathrm{N}, 114^{\circ} 25^{\prime}-116^{\circ} 8^{\prime} \mathrm{E}\right)$ is a prefecture-level light industry city located on the bank of Yangtze River in the eastern part of Hubei Province, China. With its special geographical location, Huanggang lies opposite to the industrial corridor (including Ezhou, 
Huangshi and Daye), which belongs to the economic development of Wuhan City Circle in Hubei Province. Concerned with the metalworking business in the industrial corridor, we analysed PAH concentration in street dust in 2012 and 2013 (Zhang et al., 2014; Zhang et al., 2016). Results revealed that the industrial corridor presents a potential carcinogenic risk for the exposed population, thus requiring considerable research attention. Huanggang bears heavy transportation pressure due to extensive road networks (three north-south and seven east-west major roads, such as the China National Highway G106 and G45) and two railway lines (including the Beijing-Kowloon Railway and the Beijing-Guangzhou Railway). With the influence of meteorological conditions, street dust can flow in air and transport with contaminated particles. Huanggang is situated in the boundary of potential industrial corridor cities and suffers heavy transportation pressure. Thus, studies would focus on the impact of industrial corridor on the PAHs statues in the street dust.

The objectives of this study comprised the following: 1) to determine the concentrations and profiles of PAHs in street dust collected in urban areas; 2) to identify possible PAH sources and levels; and 3) to examine the health risk for $\mathrm{PAH}$ exposure of urban street dust via ingestion, dermal contact and inhalation.

\section{MATERIALS AND METHODS}

\section{Chemicals}

16 USEPA priority PAHs: napthalen (Nap), acenaphthylene (Acy), acenaphthene(Ace), Fluorene (Flu), Phenanthrene (Phe), Anthracene (Ant), Fluoranthene (Fla), Pyrene (Pyr), Benzo[a]anthracene (BaA), Chrysene (Chr), Benzo[b]fluoranthene (BbF), Benzo[k]fluoranthene (BkF), Benzo[a]pyrene (BaP), Dibenz(a,h)anthracene (DBA), Indeno[1,2,3-cd]pyrene (IcdP), Benzo[g,h,i]perylene (BghiP)

Mix recovery surrogates were in the concentration of $200 \mu \mathrm{g} \mathrm{mL}^{-1}$, including $\mathrm{d}_{8}$-Nap, $\mathrm{d}_{10}$-Ace, $\mathrm{d}_{10}$-Phe, $\mathrm{d}_{12}-\mathrm{Chr}$ and $\mathrm{d}_{12}$-perylene. Internal standard was chosen hexamethylbenzene.

\section{Sample Collection}

Twenty-one street dust samples (Fig. 1) were collected from Huanggang City, Hubei Province, in October 2013. The sampling locations were selected from four various functional classes, namely, traffic area, business district, residential area and education district, to reveal pollution impacts from various human activities. Classification of classes, which were on the basis of the main activity with different land uses and referred to governmental administrative division as well.

Approximately $100 \mathrm{~g}$ of dust particles that accumulated on impervious surfaces of pavements and streets within a $5 \mathrm{~m}$ radius circle were collected via plastic brushes and dustpans. All samples were collected with fine particulates and stored in paper bags wrapped with solvent-rinsed aluminium. Then, the samples were sealed in polyethylene bags for transport to the laboratory. After placing in a desiccator to eliminate moisture, the samples were filtered by a $100 \mu \mathrm{m}$ sieve to remove coarse debris and small stones.

\section{Extraction Methods and Analyses}

Samples were extracted and analysed according to methods referred to in previous literature (Zhang et al., 2014; Zhang et al., 2016). The procedures were performed as follows: (a) Preparation samples (10 g) were spiked with $5 \mu \mathrm{L}$ mixed recovery surrogates and Soxhelt extraction with dichloromethane (DCM) for $24 \mathrm{~h}$. (b) The collected extract was concentrated to $2-3 \mathrm{~mL}$ volume by a rotary evaporator, and the solvent ( $n$-hexane) was exchanged. (c) The extract was purified with $1: 2(\mathrm{~V}: \mathrm{V})$ aluminium/silica gel column and eluted by $30 \mathrm{~mL}$ DCM:hexane (2:3) and (d) concentrated to $0.2 \mathrm{~mL}$ by gentle nitrogen flow. Lastly, (e) $1000 \mathrm{ng}$ internal standards were added to the $0.2 \mathrm{~mL}$ concentrated samples prior to analysis. Prior to sample preparation, aluminium and silica were cleaned with DCM for $48 \mathrm{~h}$ and muffle drying for $12 \mathrm{~h}$ at $180^{\circ} \mathrm{C}$ and $240^{\circ} \mathrm{C}$, respectively. Then, aluminium and silica were both $3 \%$ deactivated with $\mathrm{H}_{2} \mathrm{O}$ before use.

PAHs were analyzed by GC-MS (7890A/5975MSD, Agilent Technologies) equipped with a DB-5MS capillary column (30 $\mathrm{m} \times 0.25 \mathrm{~mm} \times 0.25 \mu \mathrm{m}$ film thickness). The MS was operated with electron impact (EI) ionization mode at $70 \mathrm{Ev}$. The injector and detector temperature were $270^{\circ} \mathrm{C}$ and $280^{\circ} \mathrm{C}$, respectively. The oven initial temperature was held at $60^{\circ} \mathrm{C}$ for $5 \mathrm{~min}$, afterward increased $5^{\circ} \mathrm{C} \mathrm{min}{ }^{-1}$ to $290^{\circ} \mathrm{C}$ kept for $20 \mathrm{~min}$. High-purity helium served as carrier gas with a constant flow rate of $1.0 \mathrm{~mL} \mathrm{~min}^{-1}$.

Dust samples $(0.2 \mathrm{~g})$ were pretreated with $\mathrm{HCl}(10 \%)$ to remove carbonates. After acid treatment, the samples were centrifuged and rinsed by deionised water. The retentate was oven-dried at $35^{\circ} \mathrm{C}$ for $6 \mathrm{~h}$ before analysis. Total organic carbon (TOC) was analysed by a TOC analyser (multi N/C 2100-HT1100, Analytik Jena, Germany).

\section{Quality Assurance/Quality Control}

Twelve field samples, which included one blank sample and one duplicate sample, were analysed as a batch experiment. No target PAHs were detected in the blank samples. Variation of PAHs in duplicate reached less than 15\%. Method detection limit compared with signal-to-noise ratio was $3: 1$. The mean recoveries were $58 \pm 6 \%, 82 \pm$ 9\%, $108 \pm 10 \%, 112 \pm 13 \%$ and $118 \pm 11 \%$, corresponding to $\mathrm{d}_{8}$-Nap, $\mathrm{d}_{10}$-Ace, $\mathrm{d}_{10}$-Phe, $\mathrm{d}_{12}$-Chr and $\mathrm{d}_{12}$-perylene respectively.

\section{Risk Assessment}

$\mathrm{BaP}$ considered as the most toxic PAH was utilized as the reference chemical. The total $\mathrm{BaP}$ is calculated as:

Total $\mathrm{BaP}=\Sigma i C_{i} \times \mathrm{TEF}_{\mathrm{i}}$

where $C_{i}$ is the concentration $\left(\mu g \mathrm{~kg}^{-1}\right.$ ) of individual PAHs, and toxic equivalence factor $\left(\mathrm{TEF}_{\mathrm{i}}\right)$ is relative to TEFs shown in Table 1. The incremental lifetime cancer risk (ILCR) was always used to quantitatively estimate the exposure integrated risk for environment based on the 


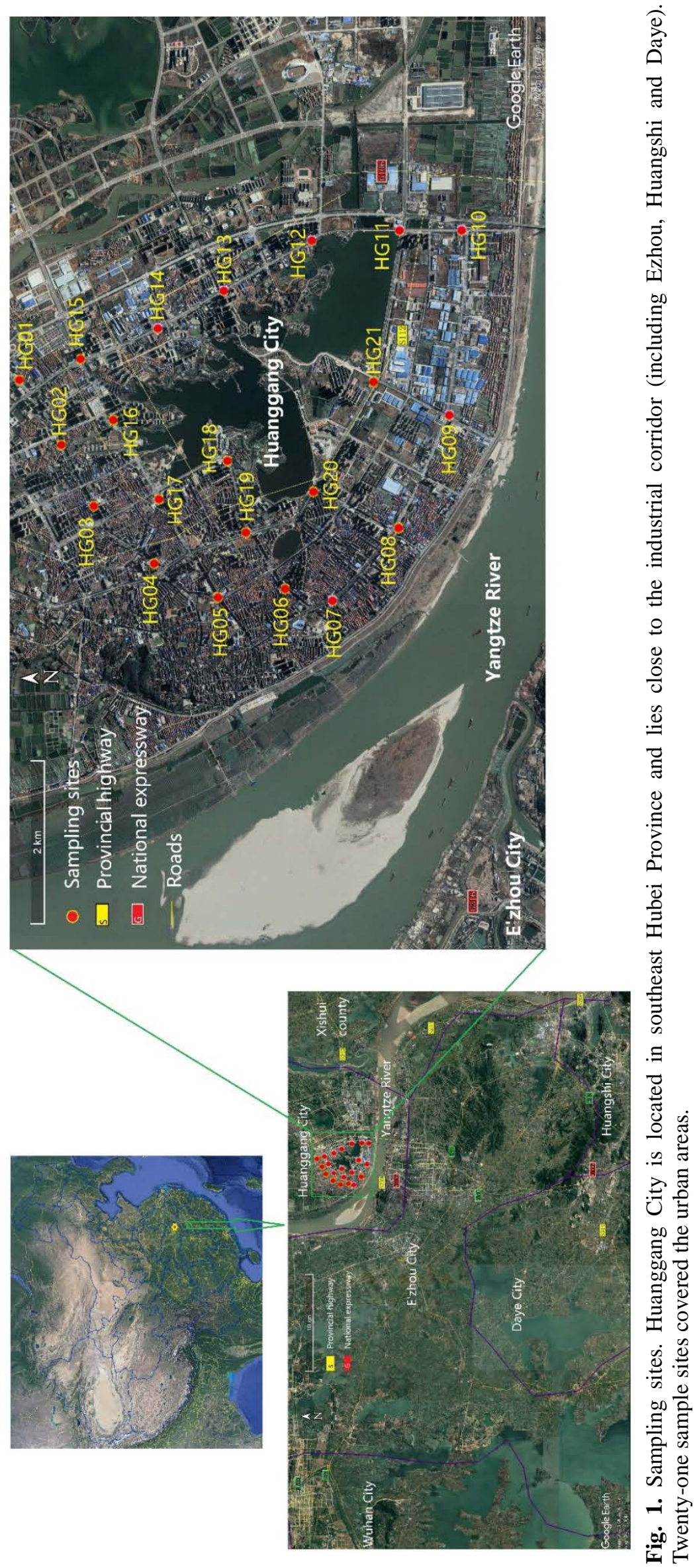


Table 1. Summary of PAHs properties, concentrations $\left(\mu \mathrm{g} \mathrm{kg}^{-1}\right)$ and TOC $\left(\mathrm{g} \mathrm{kg}^{-1}\right)$ of street dust in urban area.

\begin{tabular}{|c|c|c|c|c|c|c|c|c|c|}
\hline Chemicals & Abbreviation & rings & PAH Structures & $\mathrm{TEF}^{\mathrm{a}}$ & Max & Min & Ave. & Std. & Median \\
\hline Naphthalene & $\mathrm{NaP}$ & 2 & & 0.001 & 176.16 & 41.52 & 97.92 & 35.32 & 97.05 \\
\hline Acenaphthylene & Acy & 3 & & 0.001 & 237.50 & 10.39 & 84.48 & 54.19 & 75.50 \\
\hline Acenaphthene & Ace & 3 & & 0.001 & 67.82 & 5.01 & 15.00 & 14.01 & 11.49 \\
\hline Fluorene & Flu & 3 & & 0.001 & 73.15 & 16.28 & 37.19 & 15.74 & 35.16 \\
\hline Phenanthrene & Phe & 3 & & 0.001 & 668.15 & 125.88 & 305.40 & 128.12 & 290.10 \\
\hline Anthracene & Ant & 3 & & 0.01 & 92.84 & 16.17 & 42.51 & 21.13 & 38.07 \\
\hline Fluoranthene & Fla & 4 & & 0.001 & 924.55 & 99.83 & 373.05 & 184.25 & 355.99 \\
\hline Pyrene & Pyr & 4 & & 0.001 & 604.66 & 64.65 & 248.64 & 126.96 & 234.50 \\
\hline Benzo[a]anthracene & $\mathrm{BaA}$ & 4 & & 0.1 & 199.96 & 26.26 & 86.08 & 46.72 & 70.20 \\
\hline Chrysene & Chr & 4 & & 0.01 & 486.43 & 64.87 & 225.40 & 107.85 & 212.42 \\
\hline Benzo[b]fluoranthene & $\mathrm{BbF}$ & 5 & & 0.1 & 291.55 & 31.07 & 114.88 & 66.54 & 102.42 \\
\hline Benzo[k]fluoranthene & $\mathrm{BkF}$ & 5 & & 0.1 & 145.94 & 15.56 & 57.50 & 33.31 & 51.27 \\
\hline Benzo[a]pyrene & $\mathrm{BaP}$ & 5 & & 1 & 167.33 & 16.12 & 67.40 & 42.19 & 53.32 \\
\hline Dibenz(a,h)anthracene & DBA & 5 & & 1 & 44.11 & 3.96 & 17.10 & 10.74 & 14.27 \\
\hline Indeno[1,2,3-cd]pyrene & IcdP & 6 & & 0.1 & 103.16 & 9.70 & 41.27 & 25.45 & 35.73 \\
\hline \multirow[t]{5}{*}{ Benzo[g,h,i]perylene } & BghiP & 6 & & 0.01 & 116.63 & 12.63 & 48.30 & 28.54 & 42.04 \\
\hline & LMW & & & & 1261.81 & 254.23 & 582.49 & 251.07 & 553.64 \\
\hline & HMW & & & & 3078.86 & 344.64 & 1279.61 & 662.74 & 1203.75 \\
\hline & $\sum$ PAHs & & & & 4340.67 & 622.97 & 1862.10 & 907.92 & 1775.33 \\
\hline & TOC & & & & 15.01 & 2.82 & 6.60 & 3.06 & 5.77 \\
\hline
\end{tabular}

Notes: Std. denotes standard deviation; LMW PAHs denotes low molecular weight 2-3 ring PAHs; HMW PAHs denotes high molecular weight 4-6 ring PAHs. ${ }^{\text {a }}$ The Toxic equivalency effects (TEFs) were used to quantify the carcinogenicity of other PAHs relative to BaP and to estimate the BaP equivalent concentration (Nisbet and LaGoy, 1992).

models and parameters referring to the Risk Assessment Guideline of USEPA (2011, 2017) and related publication in Table 2 (Wang et al., 2011; Zhang et al., 2014).

$$
\begin{aligned}
& \mathrm{ILCRs}_{\text {ingestion }}= \\
& \frac{\mathrm{CS} \times\left(\mathrm{CSF}_{\text {ingestion }} \times \sqrt[3]{\mathrm{BW} / 70}\right) \times \mathrm{IR}_{\text {ingestion }} \times \mathrm{EF} \times \mathrm{ED} \times \mathrm{CF}}{\mathrm{BW} \times \mathrm{AT}}
\end{aligned}
$$

$$
\begin{aligned}
& \mathrm{ILCRs}_{\text {dermal }}= \\
& \mathrm{CS} \times\left(\mathrm{CSF}_{\text {dermal }} \times \sqrt[3]{\mathrm{BW} / 70}\right) \times \mathrm{SA} \times \mathrm{AF} \times \mathrm{ABS} \times \mathrm{EF} \times \mathrm{ED} \times \mathrm{CF} \\
& \mathrm{BW} \times \mathrm{AT}
\end{aligned}
$$

$$
\begin{aligned}
& \mathrm{ILCRs}_{\text {inhalation }}= \\
& \mathrm{CS} \times\left(\mathrm{CSF}_{\text {inhalation }} \times \sqrt[3]{\mathrm{BW} / 70}\right) \times \mathrm{IR}_{\text {inhalation }} \times \mathrm{EF} \times \mathrm{ED} \\
& \mathrm{BW} \times \mathrm{AT} \times \mathrm{PEF}
\end{aligned}
$$

CS (mg kg-1) converts for the sum of BaP equivalent concentration (seeing Eq. [1]); CSF (mg kg-1 $\left.\mathrm{d}^{-1}\right)^{-1}$ is the carcinogenic slope factor; $\mathrm{IR}_{\text {ingestion }}$ is the soil ingestion rate $\left(\mathrm{mg} \mathrm{d}^{-1}\right)$, EF $\left(\mathrm{d} \mathrm{yr}^{-1}\right)$ is the exposure frequency; ED (yr) is about the exposure duration; CF $\left(\mathrm{kg} \mathrm{mg}^{-1}\right)$ is the conversion factors $10^{-6}$; BW (kg) is the average body weight; AT (d) is the range of average life; $\mathrm{SA}\left(\mathrm{cm}^{2}\right)$ is dermal exposure area; AF (mg cm${ }^{-2}$ ) is the dermal adherence factor; ABS (unitless) is the dermal adsorption faction; $\mathrm{IR}_{\text {inhalation }}$ is the inhalation rate $\left(\mathrm{m}^{3} \mathrm{~d}^{-1}\right)$, PEF $\left(\mathrm{m}^{3} \mathrm{~kg}^{-1}\right)$ is particle emission factor. $\mathrm{CSF}_{\text {ingestion, }} \mathrm{CSF}_{\text {dermal }}$ and $\mathrm{CSF}_{\text {inhalation }}$ corresponded 
Table 2. Values of parameters used for estimation of the ILCRs.

\begin{tabular}{|c|c|c|c|c|c|c|c|}
\hline \multirow{2}{*}{ Exposure parameters } & \multirow{2}{*}{ Unit } & \multicolumn{2}{|c|}{ Childhood } & \multicolumn{2}{|c|}{ Adolescence } & \multicolumn{2}{|c|}{ Adulthood } \\
\hline & & Male & Female & Male & Female & Male & Female \\
\hline Body weight (BW) & $\mathrm{kg}$ & 14.3 & 13.6 & 48.1 & 45.4 & 62.8 & 54.7 \\
\hline Ingestion rate ( $\left.\mathrm{IR}_{\text {ingestion }}\right)$ & $\mathrm{mg} \mathrm{d}^{-1}$ & 200 & 200 & 100 & 100 & 100 & 100 \\
\hline Exposure frequency (EF) & $\mathrm{d} \mathrm{yr}^{-1}$ & 350 & 350 & 350 & 350 & 350 & 350 \\
\hline Exposure duration (ED) & yr & 6 & 6 & 14 & 14 & 30 & 30 \\
\hline Average life span (AT) & $\mathrm{d}$ & $72 \times 365$ & $72 \times 365$ & $72 \times 365$ & $72 \times 365$ & $72 \times 365$ & $72 \times 365$ \\
\hline Surface area (SA) & $\mathrm{cm}^{2} \mathrm{~d}^{-1}$ & 2800 & 2800 & 2800 & 2800 & 5700 & 5700 \\
\hline Dermal surface factor (AF) & $\mathrm{Mg} \mathrm{cm}^{-2}$ & 0.2 & 0.2 & 0.2 & 0.2 & 0.07 & 0.07 \\
\hline Dermal absorption faction (ABS) & unitless & 0.13 & 0.13 & 0.13 & 0.13 & 0.13 & 0.13 \\
\hline Inhalation rate $\left(\mathrm{IR}_{\text {inhalation }}\right)$ & $m^{3} d^{-1}$ & 10.9 & 10.9 & 17.7 & 17.7 & 17.5 & 17.5 \\
\hline Particle emission factor (PEF) & $\mathrm{m}^{3} \mathrm{~kg}^{-1}$ & $1.36 \times 10^{9}$ & $1.36 \times 10^{9}$ & $1.36 \times 10^{9}$ & $1.36 \times 10^{9}$ & $1.36 \times 10^{9}$ & $1.36 \times 10^{9}$ \\
\hline
\end{tabular}

to 7.3, 25 and $3.85\left(\mathrm{mg} \mathrm{kg}^{-1} \mathrm{day}^{-1}\right)^{-1}$, respectively (Knafla et al., 2006; Peng et al., 2011).

\section{RESULTS AND DISCUSSION}

\section{PAH Concentration and Profiles}

Concentration of 16 PAHs in street dust of Huanggang City varied from $622.97 \mu \mathrm{g} \mathrm{kg}^{-1}$ (HG10) to $4340.67 \mu \mathrm{g} \mathrm{kg}^{-1}$ (HG07) with an average of $1862.10 \mu \mathrm{gg}^{-1}$ (Table 1). Average concentration $\left(\mu \mathrm{kg}^{-1}\right)$ of individual PAHs increased as follows: Ace (15) < DBA (17.1) < Flu (37) < IcdP (41.27) < Ant (42.51) < BghiP (48.3) < BkF (57.5) < $\mathrm{BaP}(67.4)<$ Acy $(84.48)<\mathrm{BaA}(86.8)<\mathrm{Nap}(97.92)<$ BbF (114.88) < Chr (225.40) < Pyr (248.64) < Phe (305.40) < Fla (373.05). Spearman correlation coefficients with individual PAHs were significantly relative to each other at $\mathrm{p}<0.01$ level and low molecular weight (LMW) and high molecular weight (HMW) (Table 3).

LMW PAHs (two to three rings) varied from $254.23 \mu \mathrm{g} \mathrm{kg}^{-1}$ to $1261.81 \mathrm{\mu g} \mathrm{kg}^{-1}$ (mean $582.49 \mu \mathrm{g} \mathrm{kg}^{-1}$ ) accounting for $27 \%-45 \%$ of total PAHs. By contrast, HMW PAHs (four to six rings) varied from $344.64 \mathrm{\mu g} \mathrm{kg}^{-1}$ to $3078.86 \mu \mathrm{g} \mathrm{kg}^{-1}$ (mean: $1279.61 \mu \mathrm{g} \mathrm{kg}^{-1}$ ) accounting for $55 \%-73 \%$ of $\Sigma_{16}$ PAHs. Similar to Guangzhou (China) (Wang et al., 2011), Tianjin (China) (Yu et al., 2014) and Bushehr (Iran) (Keshavarzi et al., 2017), HMW PAHs were dominant in street dust samples. Two available reasons, in terms of chemical properties and emission pathways, can provide possible explanation for such results. Normally, the properties of PAHs (e.g., vapour pressure and $\mathrm{K}_{O W}$ ) determine the compound vapour-particle partitioning, corresponding to the available fraction of long-range atmospheric transportation via air phase and proportion in the solid phase (Chung et al., 2007). Given their high atmospheric motilities, LMW PAHs can be transported from remote areas or long-range atmospheric deposition (Agarwal et al., 2009) and losses from particles, decreasing LMW PAH concentration in street dust. Compared with LMW PAHs, HMW compounds can feature additional emission sources via domestic heating, industries and agriculture-related activities (Xing et al., 2011).

Organic matter is a principal factor controlling sorption of organic chemicals in soil or sediment and is constantly examined by TOC (Nam et al., 2008). Previous studies have also shown the highly positive correlation between PAHs and TOC in soils (Wang et al., 2009). In the present study, however, TOC presented a weak correlation with PAHs (Table 3); this trend was similar as that observed in Dalian (Wang et al., 2009) and Lanzhou areas (Jiang et al., 2014). The possible reason can be the different physicalchemical components in different media, leading to various organic matter distributions. As an example, organic matter distributions in soil and dust differ. Soil is the main homogenous humic substance (Senesi, 1992). On the other hand, dusts, the origin of organic matters, are complex and comprise a mixture of atmospheric aerosol, asphalt particles, tire particles, sands and soils (Takada et al., 1990). Therefore, PAH correlation between soil and dust varies.

\section{PAH Geographical Distribution at Different Functional Districts}

Fig. 2 shows the PAH levels of different function areas. The traffic area is located at the traffic-busy intersection of Dongmen Road (north downtown) and near Mingzhu Road (belonging to Beijing-Kowloon high-speed railway). The business district includes seven sites covering the entire downtown, representing the commercial centre of human activities. The residential area is located at southern downtown part, which covers residential communities. The education district includes five sampling sites close to preliminary and middle schools.

Mean concentration ( $\mu \mathrm{g} \mathrm{kg}^{-1}$ ) of 16 PAHs was in the following order: education district (2382) $>$ traffic area (2265.20) > business district (1566) > residential area (1225). This decreasing tendency was very similar to that of Xi'an City, Northwest China (Wang et al., 2016). Normally, roads in the education district suffer heavy traffic jams at approximately 8 AM or 5 PM when parents drive or pick up their children from school. Vehicle speed and spread of pollutants can explain PAH dilution and accumulation in street dust (Zhai et al., 2017). Considering the weathering of materials from street surface, automobile exhaust, tire particles and atmospherically deposited materials act as origin input of PAHs in streets (Takada et al., 1991). Thus, the highest PAHs, which was observed in the education district, possibly resulted from traffic emission. Compared with other functional districts, the residential yielded the lowest PAH level, similar to a report on PAH distribution 


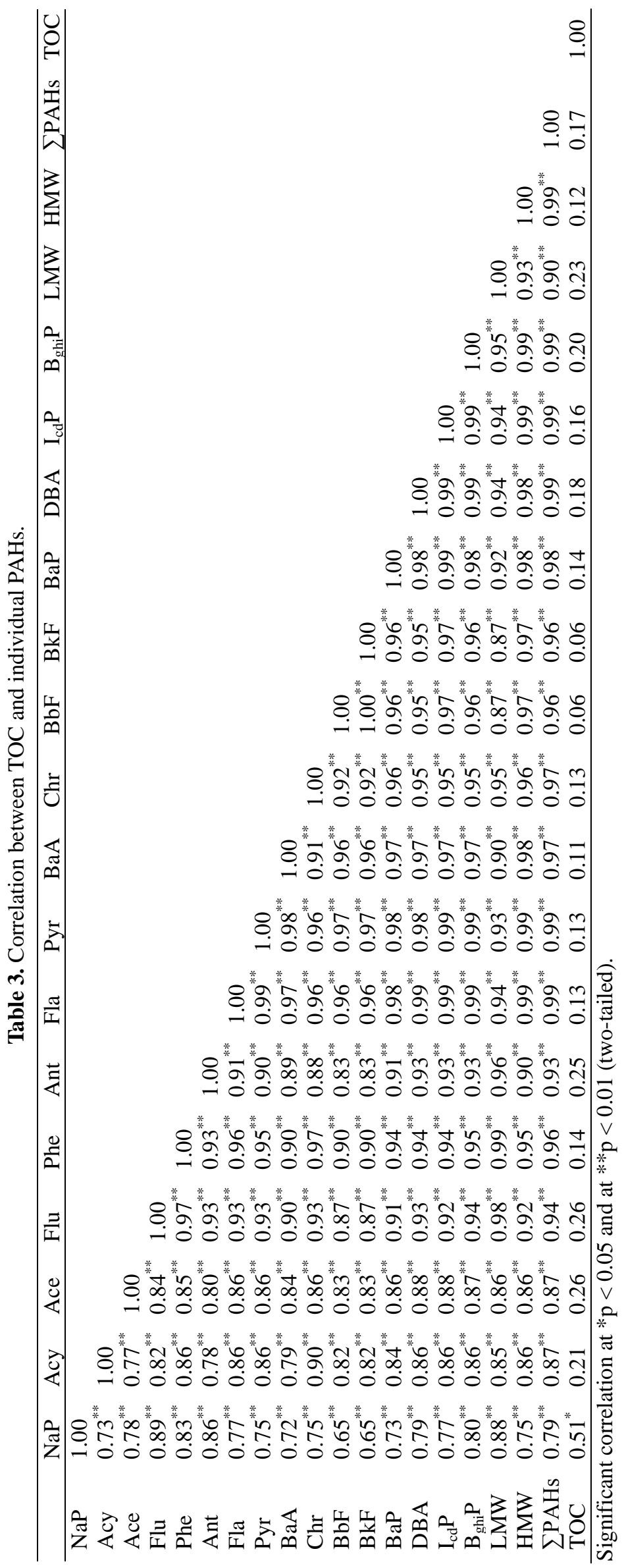




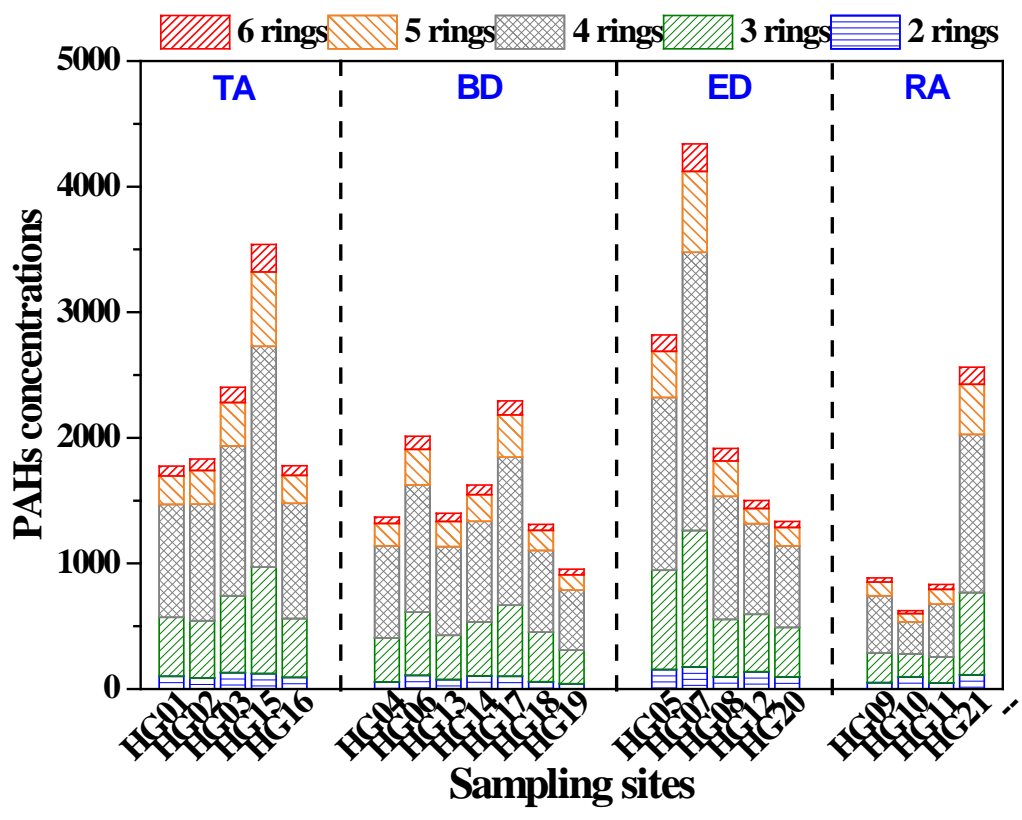

Fig. 2. Functional districts on 2-6 rings $\mathrm{PAH}$ concentrations in urban street dust $\left(\mu \mathrm{g} \mathrm{kg}^{-1}\right)$.

in street dust of Guangzhou (Wang et al., 2011). Considerable distance from vehicle emissions and frequency of city pavement cleaning can also efficiently reduce $\mathrm{PAH}$ concentration.

\section{Composition and Potential Sources of PAH Contamination}

$\mathrm{PAH}$ ratios, including Ant/(Ant + Phe) versus Flu/(Flu + Pyr) and $\mathrm{BaA} /(\mathrm{BaA}+\mathrm{Chr})$ versus IcdP/(IcdP + BghiP), are used to discriminate source of PAHs (Yunker et al., 2002; Zhang et al., 2006; Jiang et al., 2014; Hamid et al., 2017). An Ant/(Ant + Phe) ratio of 0.1 can distinguish petroleum $(<0.1)$ and dominance of combustion $(>0.1)$ source. On the other hand, the ratio of Flu/(Flu + Pyr) is used as indicator of petroleum input $(<0.4)$ and biomass and coal combustion $(>0.5$ ); a ratio between 0.4 and 0.5 is characteristic of petroleum combustion (such as traffic emission). The ratios of $\mathrm{BaA} /(\mathrm{BaA}+\mathrm{Chr})<0.2$ and IcdP/(IcdP + BghiP $)<0.2$ both indicate petroleum-derived source. When $\mathrm{BaA} /(\mathrm{BaA}$ + Chr) increases between 0.2 and 0.35 and IcdP/(IcdP + BghiP) between 0.2 and 0.5, PAHs mainly originate from petroleum combustion (e.g., liquid fossil fuel, vehicle and crude oil). Ratios of $\mathrm{BaA} /(\mathrm{BaA}+\mathrm{Chr})$ and $\mathrm{IcdP} /(\mathrm{IcdP}+$ BghiP) that are higher than 0.35 and 0.5 , respectively, strongly indicate contribution of coal and biomass.

Fig. 3 displays the PAH ratio scatter plots of four different function areas observed in the present study. The ratios of 18 sampling sites were influenced by biomass and coal combustion, however, HG04 (business district), HG09 (residential area) and HG16 (traffic area) were influenced by petroleum and biomass and coal combustion. The development status and energy structures are predominant to tracing PAH sources (Hafner et al., 2005). Referring to Xu et al. (2006) on PAH emission in China in 2003, biomass (firewood and straw), domestic coal and coking industry were the main PAH sources in Hubei Province. Until 2013, based on energy statistical data from the government, raw coal consumption in Huanggang area totalled $3.73 \times 10^{6}$ tons, accounting for $81.7 \%$ of total energy consumption (NBSC, 2014). This finding agrees well with the results on the ratios of predicted coal combustion source.

Based on $\mathrm{BaA} /(\mathrm{BaA}+\mathrm{Chr})$ versus IcdP/(IcdP + BghiP) ratios, PAHs in 20 sampling sites (except HG21) came from petroleum combustion, which may be influence by traffic emission. On the other hand, HG21 site in residential area was influenced by mix sources, including coal and biomass or petroleum combustion. As mentioned in the Introduction, traffic emission caused by heavy transportation burden (e.g., G45, G106, Beijing-Guangzhou Railway and BeijingKowloon Railway) can be the main contributors in PAH sources of Huanggang area.

Considering Spearman's coefficients of Ezhou (Zhang et al., 2016), Huanggang and the industrial corridor (Zhang et al., 2014), significantly positive correlations were observed in these areas, with $r>0.75$ (Table 4). These results indicate that PAHs may stem from the same source, i.e., traffic emissions and bio/coal combustion. Such findings are also identical with the results observed in previous studies between Ezhou and the industrial corridor.

\section{Comparison of PAH Concentrations from Other Areas}

Table 2 reveals the $\sum_{16} \mathrm{PAH}$ concentrations, which were compared with published studies. Seven metropolises were selected to represent five regions of China, i.e., North (Dalian, Tianjin and Beijing), Northwest (Lanzhou and Xi'an), East (Shanghai) and South (Guangdong). Compared with the mean value of $\sum_{16}$ PAHs, the data in Huanggang were relatively lower than those of the mentioned cities except for Beijing. Enormous differences in economic development, population density, emission rates and patterns were observed among various cities in China (Xu et al., 2006); such condition can lead to various $\mathrm{PAH}$ distributions in street 
(a)

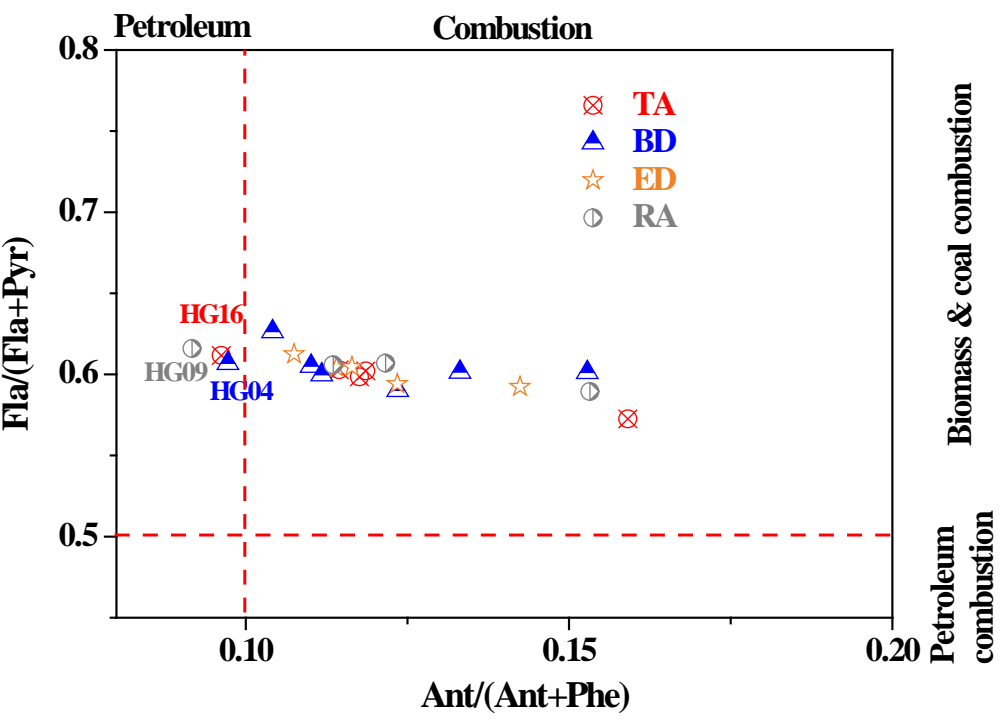

(b)

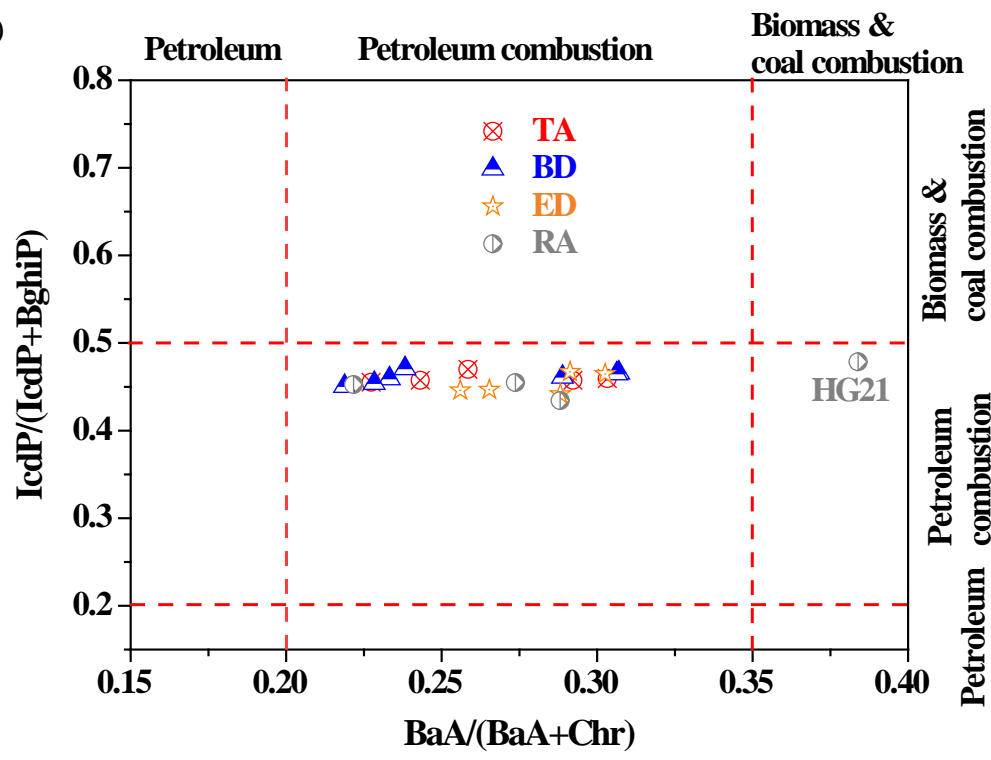

Fig. 3. Scatterplot of isomer ratios for PAHs sources. (a) Ant/(Ant + Phe) versus Fla/(Fla + Pyr); (b) BaA/(BaA + Chr) versus IcdP/(IcdP + BghiP).

Table 4. Spearman’s correlation coefficients for individual PAHs in street dust among three cities.

\begin{tabular}{llll}
\hline & Ezhou $^{\mathrm{a}}$ & Huanggang & Industrial corridor $^{\mathrm{b}}$ \\
\hline Ezhou & 1.00 & & \\
Huanggang & $0.95^{* *}$ & 1.00 & 1.00 \\
Industrial corridor & $0.86^{* *}$ & $0.75^{* *}$ & 1.00 \\
\hline
\end{tabular}

a referred to the data of Zhang et al. in 2016 (Zhang et al., 2016).

${ }^{\mathrm{b}}$ referred to the data of Zhang et al. in 2014 (Zhang et al., 2014).

** Correlation is significant at the 0.01 level (2-tailed).

dust. With the same energy structures in Hubei Province (Xu et al., 2006), Huanggang area's PAH concentration was lower than that of heavy industrial cities Ezhou and the industrial corridor. When compared with other cities in the world, Mashhad (Iran), Newcastle-upon-Tyne (England), Kumasi (Ghana), Asansol (India) and Ulsan (Korea) feature higher PAH concentrations than Huanggang City, whereas that of Bushehr (Iran) is lower than the value observed in this study.

\section{Risk Assessment}

Normally, the body served as outer boundary to control the process of chemicals crossing human body. It mainly depended on the skin and the openings into the body such 
Table 5. Comparison of PAH concentrations $\left(\mu g \mathrm{~kg}^{-1}\right)$ from different areas around the world.

\begin{tabular}{lllll}
\hline Location & Number PAHs & Ranges $\left(\mu \mathrm{kg}^{-1}\right)$ & Average & References \\
\hline Dalian, Northern China & 24 & $1890-17070$ & 7460 & (Wang et al., 2009) \\
Tianjin, Northern China & 16 & $538-34320$ & 7994 & (Yu et al., 2014) \\
Beijing, Northern China & 16 & $36-7231$ & 1136 & (Zhai et al., 2017) \\
Lanzhou, Northwest China & 16 & $1240-10700$ & 3900 & (Jiang et al., 2014) \\
Xi’an, Northwest China & 16 & $7259-18475$ & 10620 & (Wei et al., 2015) \\
Shanghai, East China & 16 & $9176-32573^{\mathrm{a}}$ & $20648^{\mathrm{a}}$ & (Liu et al., 2007) \\
& & $6875-27766^{\mathrm{b}}$ & $14098^{\mathrm{b}}$ & \\
Guangzhou, South China & 16 & $840-12300$ & 4800 & (Wang et al., 2011) \\
Industrial corridor, central China & 16 & $1720-13170$ & 4910 & (Zhang et al., 2014) \\
E’zhou, central China & 16 & $1350-9600$ & 4430 & (Zhang et al., 2016) \\
Ulsan, Korea & 16 & $19690-154640$ & & (Lee and Dong, 2010) \\
Bushehr, Iran & 16 & $73.6-9491$ & 1116 & (Keshavarzi et al., 2017) \\
Mashhad, Iran & 16 & $764-8986.7$ & 3183.45 & (Najmeddin et al., 2018) \\
Newcastle upon Tyne, England & 16 & $500-95000$ & & (Lorenzi et al., 2011) \\
Kumasi, Ghana & 28 & $181-7770$ & 2571 & (Bandowe and Nkansah, 2016) \\
Asansol India & 16 & $1708-9688$ & 4532 & (Gope et al., 2018) \\
Huanggang, central China & 16 & $559.89-4399.94$ & 1862.10 & This study \\
\hline
\end{tabular}

${ }^{\mathrm{a}}$ and ${ }^{\mathrm{b}}$ represented that samples collected in winter and summer, respectively.

as the mouth, the nostrils, and punctures and lesions in the skin. In most cases, the ILRC model was applied to evaluate the long-term carcinogenic risk among the public. It was on the basis of five items for the difference chemicals in absorption across body barriers (USEPA, 1997): (1) the pathways of exposure, (2) the environmental media which transports the contaminant, (3) the contaminant concentration, (4) the exposure time, frequency, and duration, and (5) the exposed population. In fact, ingestion, inhalation and dermal contact were classified as three major exposure pathways, which corresponding to oral, respiratory and dermal, respectively. Furthermore, other assessment parameters in item (4) were empirical and estimates values from amount of experiments (Table 2). In this study, we chose three types of populations to evaluate the risk of street dust. They were children, adolescence and adults, which were depended on the ages.

A probabilistic risk assessment framework was showing in Fig. 4. The decreasing trend exposure was as follows: dermal contact $>$ ingestion $>$ inhalation, corresponding to that in Ezhou and the industrial corridor (Zhang et al., 2014; Zhang et al., 2016). Cancer risk levels for ingestion and dermal contact route ranged from $10^{-7}$ to $10^{-6}$ in all dust samples, whereas inhalation cancer risks spanned from $10^{-12}$ to $10^{-11}$. Given the cancer risk of inhalation, the re-suspended particles ranged from $10^{-11}$ to $10^{-9}$. These values were nearly $10^{3}-10^{6}$ times lower than those of dermal contact and ingestion routes. Thus, these findings can mainly explain the slightly decreasing incremental lifetime cancer risks (ILCRs) of inhalation compared with the other two exposure pathways and negligible contribution to total ILCRs.

ILCRs for females were slightly lower than those for males when compared with all the three routes based on the assumption that female body weight is lower than that of males. Accompanied with increasing age, ILCR of dermal contact and inhalation increased in the order of children
$<$ adolescence $<$ adults. This finding can be explained by the different dermal exposure areas and exposure duration. However, children are the most sensitive subpopulation of ingestion cancer risk. Children are likely to ingest several contaminated dusts owing to hand-to-mouth activities (Meza-Figueroa et al., 2007). Early development of organs and nervous and immune systems can probably promote carcinogen sensitivity in children (Maertens et al., 2008). Considering the low body weight of children, inhalation rates per unit of body weight of the same volume pollutants are assumed to be higher in children than in adults.

In terms of regulatory models, ILCR values can be divided into three interval sections relative to three different levels, i.e., virtual safety $\left(<10^{-6}\right)$, potential risk $\left(10^{-6}-10^{-4}\right)$ and high potential risk $\left(>10^{-4}\right)$ (Chen and Liao, 2006). In the present study, at $95 \%$ confidence interval, the total ILCRs for children, adolescence and adults approximated $10^{-6}-1.5 \times 10^{-5}$. These values were higher than the baseline value of acceptable risk, indicating potential carcinogenic risk. Among these values, total ILCRs in residential area for children and adolescence were lower than $10^{-6}$, thus expressing virtual safety. The highest ILCRs were measured in the education district as children and adolescents study in this district for long periods. This result should be given considerable research attention.

\section{CONCLUSION}

Sixteen priority PAHs were investigated from 21 sampling sites, which covered four different functional districts of an urban area in Huanggang City. The average concentration of PAHs reached $1862.10 \mu \mathrm{g} \mathrm{kg}^{-1}$, a moderate level compared with those of other cities, and is possibly influenced by economic development, population density and emission patterns. HMW PAHs were the dominant components and were correlated with combustion origins. The education district yielded the highest PAH concentration correlated 

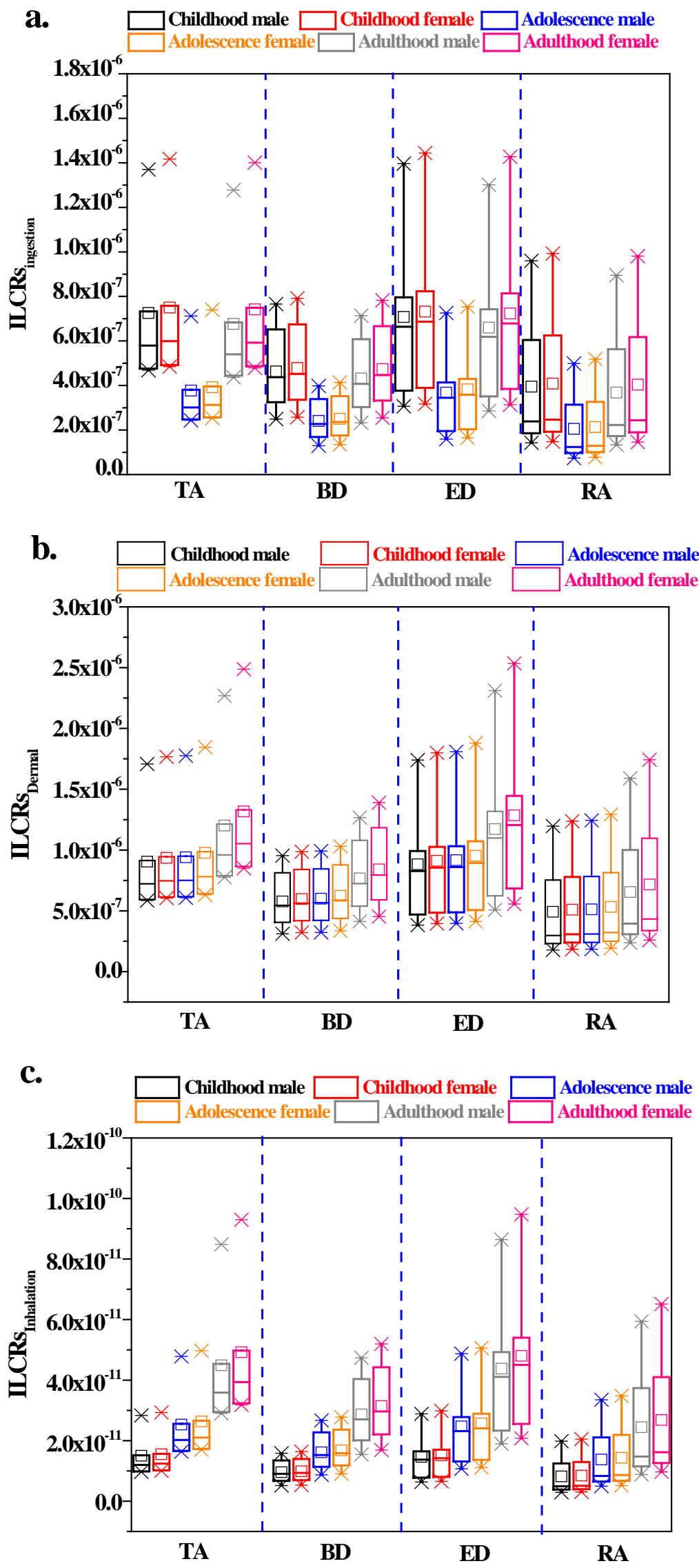

Fig. 4. Risk assessments for cancer and human exposure to PAHs via urban street dust. (a) ILCR exposure of ingestion; (b) ILCRs of dermal contact; (c) ILCRs for inhalation; and (d) total ILCRs via ingestion, dermal contact and inhalation. 


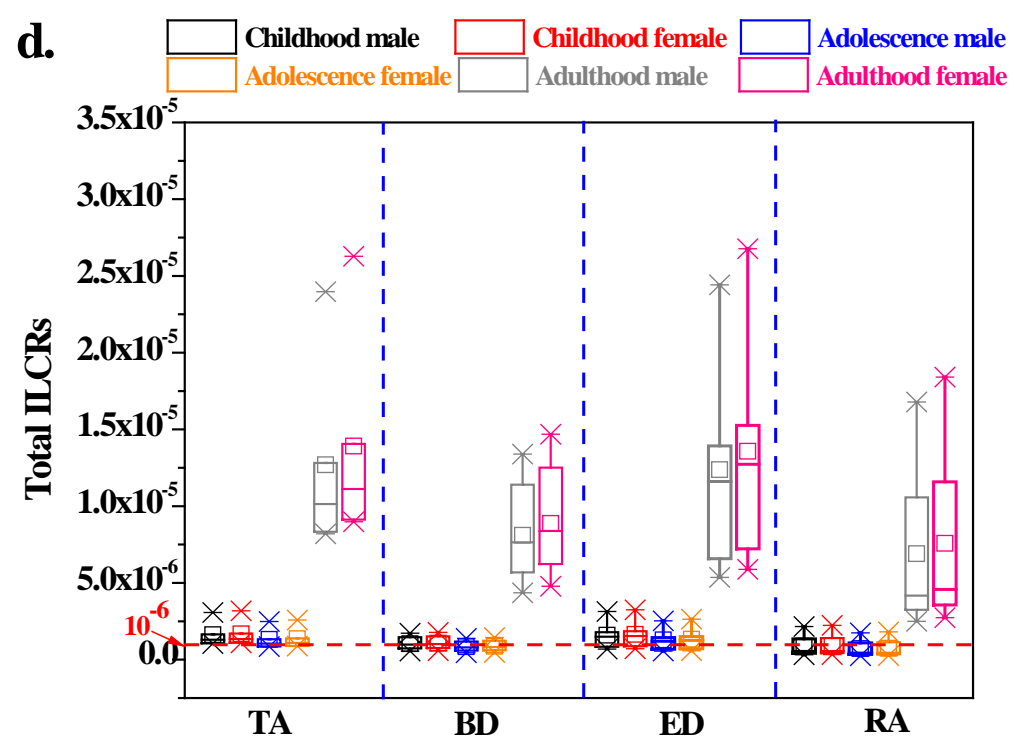

Fig. 4. (continued).

to traffic emissions derived from $\mathrm{BaA} /(\mathrm{BaA}+\mathrm{Chr})$ versus IcdP/(IcdP + BghiP). Based on Ant/(Ant + Phe) versus Flu/(Flu + Pyr) ratios, biomass and coal combustion were the main PAH emission sources in this area, similar to the result with energy structure in Hubei Province. TOC cannot serve as an indicator for tracing $\mathrm{PAH}$ profiles owing to the weak correlation coefficients between these variables. The residential area was relatively virtually safe for children and adolescents but presented a potential health risk based on ILCR data. Therefore, residential areas should also be given considerable research attention.

\section{ACKNOWLEDGEMENTS}

The research was supported by the National Key Research and Development Program of China (2017YFC0212602), the Hubei Universities of Outstanding Young Scientific and Technological Innovation Team Plans (T201729), the National Natural Science Foundation of China (41603117), the Outstanding Youth Science and Technology Innovation Team Projects of Hubei Polytechnic University (13xtz07), the Special Scientific Research Funds for National Basic Research Program of China (2013FY112700).

\section{REFERENCES}

Agarwal, T., Khillare, P.S., Shridhar, V. and Ray, S. (2009). Pattern, sources and toxic potential of PAHs in the agricultural soils of Delhi, India. J. Hazard. Mater. 163: 1033-1039.

Bandowe, B.A.M. and Nkansah, M.A. (2016). Occurrence, distribution and health risk from polycyclic aromatic compounds (PAHs, oxygenated-PAHs and azaarenes) in street dust from a major West African Metropolis. Sci. Total Environ. 553: 439-449.

Boström, C.E., Gerde, P., Hanberg, A., Jernström, B., Johansson, C., Kyrklund, T., Rannug, A., Törnqvist, M.,
Victorin, K. and Westerholm, R. (2002). Cancer risk assessment, indicators, and guidelines for polycyclic aromatic hydrocarbons in the ambient air. Environ. Health Perspect. 110: 451.

Chen, S.C. and Liao, C.M. (2006). Health risk assessment on human exposed to environmental polycyclic aromatic hydrocarbons pollution sources. Sci. Total Environ. 366: 112-123.

Chung, M.K., Hu, R., Cheung, K.C. and Wong, M.H. (2007). Pollutants in Hong Kong soils: Polycyclic aromatic hydrocarbons. Chemosphere 67: 464-473.

Gope, M., Masto, R.E., George, J. and Balachandran, S. (2018). Exposure and cancer risk assessment of polycyclic aromatic hydrocarbons (PAHs) in the street dust of Asansol city, India. Sustainable Cities Soc. 38: 616-626.

Hafner, W.D., Carlson, D.L. and Hites, R.A. (2005). Influence of local human population on atmospheric polycyclic aromatic hydrocarbon concentrations. Environ. Sci. Technol. 39: 7374-7379.

Hamid, N., Syed, J.H., Junaid, M., Mahmood, A., Li, J., Zhang, G. and Malik, R.N. (2017). Elucidating the urban levels, sources and health risks of polycyclic aromatic hydrocarbons (PAHs) in Pakistan: Implications for changing energy demand. Sci. Total Environ. 619620: 165-175.

Jiang, Y., Hu, X., Yves, U.J., Zhan, H. and Wu, Y. (2014). Status, source and health risk assessment of polycyclic aromatic hydrocarbons in street dust of an industrial city, NW China. Ecotoxicol. Environ. Saf. 106: 11-18.

Keshavarzi, B., Abbasi H, S., Moore, F., Delshab, H. and Soltani, N. (2017). Polycyclic aromatic hydrocarbons in street dust of Bushehr City, Iran: Status, source, and human health risk assessment. Polycyclic Aromat. Compd., in Press.

Knafla, A., Phillipps, K.A., Brecher, R.W., Petrovic, S. and Richardson, M. (2006). Development of a dermal cancer slope factor for benzo[a]pyrene. Regul. Toxicol. 
Pharm. 45: 159-168.

Lee, B.K. and Dong, T.T. (2010). Effects of road characteristics on distribution and toxicity of polycyclic aromatic hydrocarbons in urban road dust of Ulsan, Korea. J. Hazard. Mater. 175: 540-550.

Liu, M., Cheng, S.B., Ou, D.N., Hou, L.J., Gao, L., Wang, L.L., Xie, Y.S., Yang, Y. and Xu, S.Y. (2007). Characterization, identification of road dust PAHs in central Shanghai areas, China. Atmos. Environ. 41: 8785-8795.

Lorenzi, D., Entwistle, J.A., Cave, M. and Dean, J.R. (2011). Determination of polycyclic aromatic hydrocarbons in urban street dust: implications for human health. Chemosphere 83: 970-977.

Maertens, R.M., Yang, X., Zhu, J., Gagne, R.W., Douglas, G.R. and White, P.A. (2008). Mutagenic and carcinogenic hazards of settled house dust I: Polycyclic aromatic hydrocarbon content and excess lifetime cancer risk from preschool exposure. Environ. Sci. Technol. 42: 1747-1753.

Martuzevicius, D., Kliucininkas, L., Prasauskas, T., Krugly, E., Kauneliene, V. and Strandberg, B. (2011). Resuspension of particulate matter and PAHs from street dust. Atmos. Environ. 45: 310-317.

Mastral, A.M. and Callen, M.S. (2000). A review on polycyclic aromatic hydrocarbon (PAH) emissions from energy generation. Environ. Sci. Technol. 34: 30513057.

Meza-Figueroa, D., De la O-Villanueva, M. and De la Parra, M.L. (2007). Heavy metal distribution in dust from elementary schools in Hermosillo, Sonora, México. Atmos. Environ. 41: 276-288.

Mostafa, A.R., Hegazi, A.H., El-Gayar, M.S. ad Andersson, J.T. (2009). Source characterization and the environmental impact of urban street dusts from Egypt based on hydrocarbon distributions. Fuel 88: 95-104.

Najmeddin, A., Moore, F., Keshavarzi, B. and Sadegh, Z. (2018). Pollution, source apportionment and health risk of potentially toxic elements (PTEs) and polycyclic aromatic hydrocarbons (PAHs) in urban street dust of Mashhad, the second largest city of Iran. J. Geochem. Explor. 190: 154-169.

Nam, J.J., Gustafsson, O., Kurt-Karakus, P., Breivik, K., Steinnes, E. and Jones, K.C. (2008). Relationships between organic matter, black carbon and persistent organic pollutants in European background soils: Implications for sources and environmental fate. Environ. Pollut. 156: 809-817.

NBSC (2014). Hubei province bureau of statistics of China. Statistical Yearbook 2014. http://www.statshb.gov.cn/tjbs/fztjbs/112170.htm.

Nisbet, I.C. and LaGoy, P.K. (1992). Toxic equivalency factors (TEFs) for polycyclic aromatic hydrocarbons (PAHs). Regul. Toxicol. Pharm. 16: 290-300.

Peng, C., Chen, W., Liao, X., Wang, M., Ouyang, Z., Jiao, W. and Bai, Y. (2011). Polycyclic aromatic hydrocarbons in urban soils of Beijing: Status, sources, distribution and potential risk. Environ. Pollut. 159: 802-808.
Rogge, W.F., Hildemann, L.M., Mazurek, M.A., Cass, G.R. and Simoneit, B.R. (1993). Sources of fine organic aerosol. 3. Road dust, tire debris, and organometallic brake lining dust: Roads as sources and sinks. Environ. Sci. Technol. 27: 1892-1904.

Senesi, N. (1992). Binding mechanisms of pesticides to soil humic substances. Sci. Total Environ. 123: 63-76.

Takada, H., Onda, T. and Ogura, N. (1990). Determination of polycyclic aromatic hydrocarbons in urban street dusts and their source materials by capillary gas chromatography. Environ. Sci. Technol. 24: 1179-1186.

Takada, H., Onda, T., Harada, M. and Ogura, N. (1991). Distribution and sources of polycyclic aromatic hydrocarbons (PAHs) in street dust from the Tokyo Metropolitan area. Sci. Total Environ. 107: 45-69.

USEPA (1997). Expoure factors handbook. EPA/600/P95/002F, Environmental Protection Agency, Office of Research and Development. Washington, DC.

USEPA (2011). Exposure factors handbook. 2011 Edition (Final Report) Environmental Protection Agency, Washington, DC, EPA/600/R-09/052F, 2011.

USEPA (2017). Regional Screening Levels (RSLs) - Generic tables, https://www.epa.gov/risk/regional-screening-levelsrsls-generic-tables-november-2017.

Wang, D.G., Yang, M., Jia, H.L., Zhou, L. and Li, Y.F. (2009). Polycyclic aromatic hydrocarbons in urban street dust and surface soil: Comparisons of concentration, profile, and source. Arch. Environ. Contam. Toxicol. 56: 173-180.

Wang, L., Tao, W., Smardon, R.C., Shi, X. and Lu, X. (2016). Characteristics, sources, and health risk of polycyclic aromatic hydrocarbons in urban surface dust: A case study of the city of Xi'an in Northwest China. Environ. Sci. Pollut. Res. Int. 23: 13389-13402.

Wang, W., Huang, M.J., Kang, Y., Wang, H.S., Leung, A.O.W., Cheung, K.C. and Wong, M.H. (2011). Polycyclic aromatic hydrocarbons (PAHs) in urban surface dust of Guangzhou, China: Status, sources and human health risk assessment. Sci. Total Environ. 409: 4519-4527.

Wei, C., Bandowe, B.A., Han, Y., Cao, J., Zhan, C. and Wilcke, W. (2015). Polycyclic aromatic hydrocarbons (PAHs) and their derivatives (alkyl-PAHs, oxygenatedPAHs, nitrated-PAHs and azaarenes) in urban road dusts from Xi'an, Central China. Chemosphere 134: 512-520.

Xing, X., Qi, S., Zhang, J., Wu, C., Zhang, Y., Yang, D. and Odhiambo, J.O. (2011). Spatial distribution and source diagnosis of polycyclic aromatic hydrocarbons in soils from Chengdu Economic Region, Sichuan Province, western China. J. Geochem. Explor. 110: 146-154.

Xu, S., Liu, W. and Tao, S. (2006). Emission of polycyclic aromatic hydrocarbons in China. Environ. Sci. Technol. 40: 702-708.

Yu, B., Xie, X., Ma, L.Q., Kan, H. and Zhou, Q. (2014). Source, distribution, and health risk assessment of polycyclic aromatic hydrocarbons in urban street dust from Tianjin, China. Environ. Sci. Pollut. Res. 21: 28172825.

Yunker, M.B., Macdonald, R.W., Vingarzan, R., Mitchell, 
R.H., Goyette, D. and Sylvestre, S. (2002). PAHs in the Fraser River basin: A critical appraisal of PAH ratios as indicators of PAH source and composition. Org. Geochem. 33: 489-515.

Zhai, Y., Yin, Z., Zhao, X., Zhang, J., Zuo, R., Wu, J., Yang, J., Teng, Y. and Wang, J. (2017). Polycyclic aromatic hydrocarbons (PAHs) in the environment of Beijing, China: Levels, distribution, trends and sources. Hum. Ecol. Risk Assess. 24: 137-157.

Zhang, H.B., Luo, Y.M., Wong, M.H., Zhao, Q.G. and Zhang, G.L. (2006). Distributions and concentrations of PAHs in Hong Kong soils. Environ. Pollut. 141: 107114.

Zhang, J., Qu, C., Qi, S., Cao, J., Zhan, C., Xing, X., Xiao, Y., Zheng, J. and Xiao, W. (2014). Polycyclic aromatic hydrocarbons (PAHs) in atmospheric dustfall from the industrial corridor in Hubei Province, Central China. Environ. Geochem. Health 37: 891-903.

Zhang, J., Zhan, C., Liu, H., Liu, T., Yao, R., Hu, T., Xiao, W., Xing, X., Xu, H. and Cao, J. (2016). Characterization of polycyclic aromatic hydrocarbons (PAHs), iron and black carbon within street dust from a steel industrial city, Central China. Aerosol Air Qual. Res. 16: 24522461.

Received for review, February 6, 2018

Revised, May 13, 2018

Accepted, May 15, 2018 